\title{
Stability Indicating RP-UPLC Method for Assay of Emtricitabine and Tenofovir Disoproxil Fumarate in Bulk and Dosage Forms
}

\author{
Bommakanti Valli Purnima ${ }^{1,2}$, Tummala Vijaya Bhaskara Reddy ${ }^{1}$, \\ Yadlapalli Srinivas Rao3, Golkonda Ramu4, Dittakavi Ramachandran ${ }^{*}$ \\ ${ }^{1}$ Department of Chemistry, Acharya Nagarjuna University, Guntur, India \\ ${ }^{2}$ Sir C. R. Reddy College for Women, Eluru, India \\ ${ }^{3}$ Regulatory Affair, B \& S Group, Vadodara, India \\ ${ }^{4}$ Sir C. R. Reddy College of Engineering, Eluru, India \\ Email: dittakavirc@gmail.com
}

Received 25 August 2015; accepted 21 September 2015; published 24 September 2015

Copyright (C) 2015 by authors and Scientific Research Publishing Inc.

This work is licensed under the Creative Commons Attribution-NonCommercial International License (CC BY-NC).

http://creativecommons.org/licenses/by-nc/4.0/

(c) (i) () Open Access

\section{Abstract}

A simple, sensitive and rapid stability indicating reverse phase ultra performance liquid chromatography (RP-UPLC) method was developed and validated for the determination of Emtricitabine (EMT) and Tenofovir disoproxil fumarate (TDF) in pure and tablet dosage forms. The chromatographic separation was achieved by using Waters (Alliance) UPLC system equipped with autosampler and photo diode array detector. A volume of $5 \mu \mathrm{L}$ of standard or test was injected into the column and the components were separated by using the mixture of $0.68 \%$ potassium dihydrogen orthophosphate buffer of $\mathrm{pH}=6$ and methanol in the ratio 45:55 v/v as mobile phase at a flow rate of $1.2 \mathrm{~mL} / \mathrm{min}$ through BEH C18 $(100 \mathrm{~mm} \times 2.1,1.8 \mu \mathrm{m})$ at ambient temperature and were detected at a wavelength of $261 \mathrm{~nm}$. System suitable parameters such as plate count and tailing factor for EMT and TDF were found to be $2427 \& 3685,1.16 \& 1.23$ respectively, and resolution between EMT and TDF peaks was found to be 3.12. The chromatographic parameters like retention time, peak area and peak height of EMT and TDF were found to be $0.684 \& 0.930,694,200 \&$ $8,778,000$ and $272,881 \& 3685$ respectively. Percent of assay of EMT and TDF in bulk and dosage forms was determined and found to be 101.48 and 103.22 respectively. Study of degradation was examined and found that the drugs were stable under degradation conditions. The present method was developed keeping the principles of green chemistry by using eco-friendly solvent methanol in mobile phase. The developed method was found to be simple, rapid and applied for the

\footnotetext{
"Corresponding author.
} 
analysis of Truvada; therefore the proposed method is recommended for the analysis of EMT and TDF in pure and tablet dosage forms in any quality control laboratories.

\author{
Keywords
}

Truvada, Emtricitabine, Tenofovir DF, Validation, Assay

\title{
1. Introduction
}

Emtricitabine (EMT), a nucleoside reverse transcriptase inhibitor is chemically known as 4-amino-5-fluoro-1[(2R,5S)-2-(hydroxymethyl)-1,3-oxathiolan-5-yl]-1,2-dihydropyrimidin-2-one. Tenofovir disoproxil fumarate (TDF) belongs to a class of antiretroviral drugs known as nucleotide analogue reverse transcriptase inhibitors, which block reverse transcriptase, a crucial viral enzyme in HIV-1 and hepatitis B virus infections. It is chemically known as (\{[(2R)-1-(6-amino-9H-purin-9-yl) propan-2-yl] oxy $\}$ methyl) phosphoric acid. Molecular formula and molecular weight of EMT and TDF were $\mathrm{C}_{8} \mathrm{H}_{10} \mathrm{FN}_{3} \mathrm{O}_{3} \mathrm{~S} \& \mathrm{C}_{9} \mathrm{H}_{14} \mathrm{~N}_{5} \mathrm{O}_{4} \mathrm{P}$ and 247.248 \& 287.213 grams per mole respectively. The molecular structures of EMT and TDF were presented in Figure 1 and Figure 2 respectively. As the development of antiviral drugs for the treatment of viral infections has become a very active area, recently the combination of Emtricitabine (EMT) and Tenofovir disoproxil fumarate (TDF) has demonstrated significantly greater human immunodeficiency virus (HIV) ribonucleic acid (RNA) suppression compared to the combination of zidovudine and lamivudine. TDF is formulated in binary mixture with the reverse transcriptase inhibitor EMT namely Truvada tablets consisting $200 \mathrm{mg}$ of EMT and $300 \mathrm{mg}$ of TDF to prevent HIV from altering the genetic material of healthy cells.

An extensive literature survey was carried out and found some simultaneous spectrophotometric methods [1]-[8] for the determination of EMT and TDF in pure and pharmaceutical formulations. Several authors developed reversed phase liquid chromatographic methods for the simultaneous estimation of EMT and TDF in tablet dosage forms [9]-[12] and biological fluids [13]. Several liquid chromatography-tandem mass spectrometric methods [14]-[18] were present in the literature for the determination of low concentrations of these drugs especially in human plasma. In addition, two HPTLC methods [19] and one RP-UPLC method [20] were reported. Different experimental methods [21]-[26] were reported for the individual determination of EMT in tablet dosage form or human plasma and for the study of related impurities in drug substance. Several methods [27]-[35] were found in the literature for the estimation of TDF in single dosage form and human plasma.<smiles>Nc1nc(=O)n(C2CSC3COC2O3)cc1F</smiles>

Figure 1. Molecular structure of EMT.

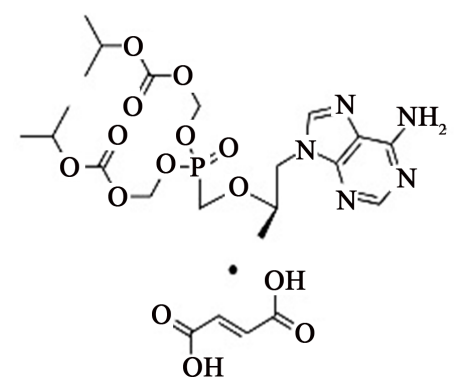

Figure 2. Molecular structure of TD. 
Since spectrophotometric methods are lack of sensitivity, though LC/MS/MS technique is highly sensitive but costly and lot of care should be taken during analysis, therefore UPLC or HPLC methods have wide applications in the analysis of pharmaceutical analysis especially in quality assessment. Though there was one UPLC method [20] reported, there is a scope to develop a new simple, rapid, economic and green UPLC method. In the reported method, buffer and acetonitrile in the ratio 55:45 v/v were used as mobile phase, where as in the developed method methanol was used instead of acetonitrile, because methanol is a universal eco-friendly green solvent. In the developed method, the detector response was found to linearly increase with respect to concentration of EMT and TDF, and the range of linearity of present method was found to be maximum when compared to the reported method. The most important application of UPLC technique is the study of impurities and forced degradation, but the reported method was found to be lack of study of forced degradation. Hence the author made some investigations on study of forced degradation to find the stability of the drugs when they were exposed to different degradation conditions. The foremost goal of the present study is to ascertain the percent of degradation when the drugs are exposed to some degradants such as acid, base, oxidant, thermal and photolytic exposure.

\section{Materials and Methods}

\subsection{Chemicals and Reagents}

Active pharmaceutical ingredient (API) of 99.8\% potency of EMT and TDF were obtained from Finoso Pharma Pvt. Ltd., Hyderabad, Telangana, India. Pharmaceutical formulations like Truvada tablets were procured from the local pharmacy. Analytical grade reagents such as methanol, potassium dihydrogen orthophosphate, hydrochloric acid, sodium hydroxide, hydrogen peroxide and HPLC grade water were procured from Merck India.

\subsection{Instrumentation}

Waters (Alliance) UPLC system equipped with auto sampler and photo diode array detector was used for the present investigation. The data acquisition was obtained from Empower-2 software.

\subsection{Preparation of Solutions}

\subsubsection{Mobile Phase}

0.68\% Potassium dihydrogen orthophosphate buffer solution was prepared by taking 6.8 grams of potassium dihydrogen orthophosphate in a clean $1000 \mathrm{~mL}$ volumetric flask and dissolved in water, made up to the mark by adjusting the $\mathrm{pH}$ of the solution equal to $\mathrm{pH}=6$ with $0.1 \mathrm{~N}$ sodium hydroxide solution. Then the resulting solution was filtered through $4.5 \mu$ filter under vacuum filtration. Mixture of buffer and methanol in the ratio 45:55 $\mathrm{v} / \mathrm{v}$ was taken, degassed in ultrasonic water bath for five minutes at room temperature and then filtered through $4.5 \mu$ filter under vacuum filtration. This was used as mobile phase and diluent.

\subsubsection{Standard Stock Solution}

Standard stock solution was prepared by precisely $20.0 \mathrm{mg}$ of EMT and $30.0 \mathrm{mg}$ of TDF standards were weighed accurately and transferred into a clean $100 \mathrm{~mL}$ volumetric flask, dissolved in $30 \mathrm{~mL}$ of diluent, sonicated for five minutes at room temperature and made up to the mark with diluent.

\subsubsection{Sample Stock Solution}

Average weight of ten Truvada tablets (200 mg of EMT and $300 \mathrm{mg}$ of TDF) was determined, grinded well and an amount of the fine powder equivalent to one tablet was accurately weighed and transferred into a clean 100 $\mathrm{mL}$ volumetric flask, dissolved in $30 \mathrm{~mL}$ of diluent, sonicated for ten minutes at room temperature, made up to the mark. Then the solution was filtered through $0.45 \mu$ filter, and made up to the mark.

\subsection{UPLC Method Development}

Ultra performance liquid chromatography (UPLC) is a novel technique used in the separation and assay of pharmaceutical formulations especially in combined drugs. This technique is found to be very useful in the study of degradation. The development of liquid chromatographic method was based on physico-chemical properties of selected drugs such as molecular weight, molecular formula, chemical structure, solubility, pKa value, UV absorption maxima and inactive ingredients. The selected drugs were completely soluble in moderately polar 
and polar solvents such as water, methanol and acetonotrile, hence a reversed phase liquid chromatographic technique was the best method in which a non polar stationary phase (a nonpolar hydrophobic packing with octyl or octa decyl functional group bonded to silica gel) and a polar mobile phase (potassium dihydrogen orthophosphate buffer solution and organic solvents like methanol) were considered. The optimum chromatographic conditions were established by testing different trials by changing one of the chromatographic conditions such as column, mobile phase and its composition, flow rate of the mobile phase, injection volume, run time, column temperature and detection wavelength keeping other constant. Finally the desired separation was achieved by injecting $5 \mu \mathrm{L}$ of standard solution into the BEH C $18(2.1 \times 100 \mathrm{~mm}, 1.8 \mu \mathrm{m})$ column maintained at ambient temperature; elution was carried out by using mobile phase at a flow rate of $1.2 \mathrm{~mL} / \mathrm{min}$, and the detection at wavelength of $261 \mathrm{~nm}$.

\subsection{Method Validation}

Validation is a procedure having of documental evidence to demonstrate method is able or not to produce the expected results under the stated experimental conditions.

\subsubsection{System Suitability Parameters}

Exactly $3.0 \mathrm{~mL}$ of standard stock solution was accurately measured, transferred into a $10 \mathrm{~mL}$ volumetric flask and diluted up to the mark with diluents. The concentration of the resulting solution was found to be $60 \mu \mathrm{g} / \mathrm{mL}$ of EMT and $90 \mu \mathrm{g} / \mathrm{mL}$ of TDF respectively. Then precisely $5 \mu \mathrm{L}$ of the this solution was injected into the column in triplicate, $0.68 \%$ Potassium dihydrogen orthophosphate buffer solution and methanol in the ration 45:65 $\mathrm{v} / \mathrm{v}$ were allowed to flow through the column at a rate of $1.2 \mathrm{~mL}$ per min from two separate channels, and the response of the instrument was recorded at $261 \mathrm{~nm}$ as a function of time for a run time of $4.0 \mathrm{~min}$. A typical system suitable chromatogram was presented in Figure 3.

\subsubsection{Precision}

Precision describes the reproducibility of results under a set of experimental conditions. To find out system precision, exactly $3.0 \mathrm{~mL}$ of standard stock solution was accurately transferred into a $10 \mathrm{~mL}$ volumetric flask and diluted up to the mark with diluents, then exactly $5 \mu \mathrm{L}$ of the this solution was injected six times into column, chromatograms were recorded under the optimized conditions and chromatographic parameters were evaluated. In the study of method precision, $3.0 \mathrm{~mL}$ of sample stock solution was accurately transferred into six separate 10 $\mathrm{mL}$ volumetric flasks and diluted up to the mark with diluents, exactly $5 \mu \mathrm{L}$ of each of these solutions was injected into the column, chromatograms were recorded and chromatographic parameters were obtained under similar conditions.

\subsubsection{Accuracy}

Accuracy describes the correctness of an experimental result expressed as the closeness of the measurement to the true or accepted value. The study of accuracy was carried out at three different levels i.e. $50 \%, 100 \%$ and

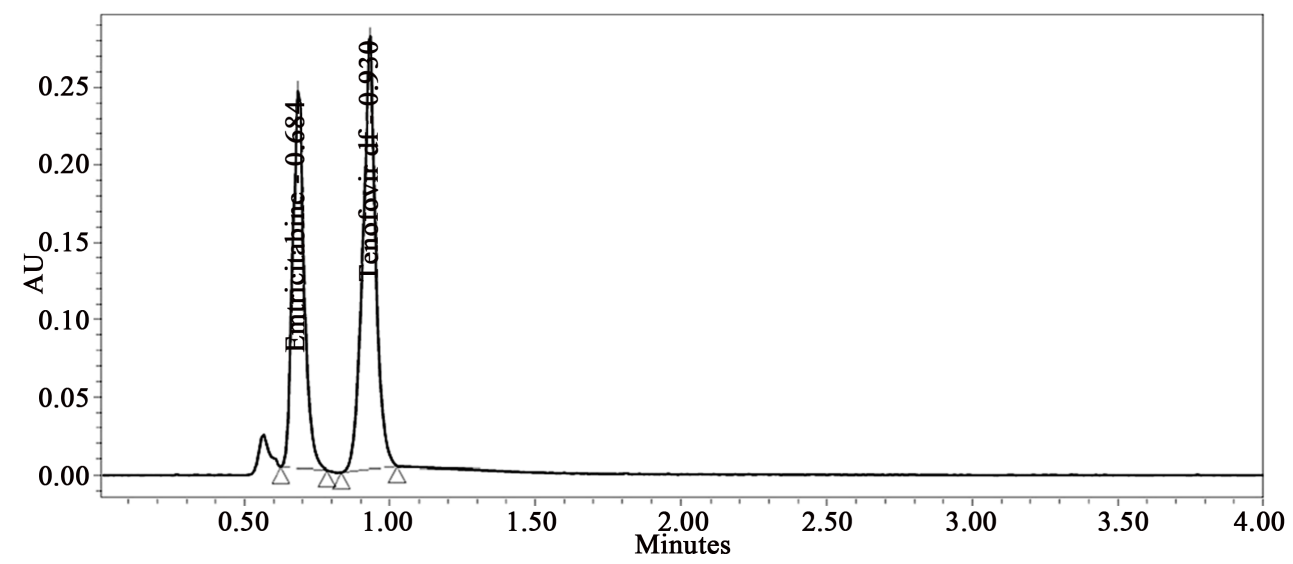

Figure 3. System suitable UPLC chromatogram of EMT and TDF. 
$150 \%$ with respect to target concentration by standard addition method in which known amounts of standards were added to pre-analyzed sample. An amount of tablet fine powder equivalent to $20 \mathrm{mg}$ of EMT and $30 \mathrm{mg}$ of TDP was taken in three different $100 \mathrm{~mL}$ volumetric flasks, 10/40/90 mg of EMT \& 30/60/90 mg of TDF was added, dissolved in $70 \mathrm{~mL}$ of diluents, sonicated for ten minutes, made up to the mark, filtered through $0.45 \mu$ membrane filter, and then exactly $3 \mathrm{~mL}$ of the filtrate was accurately transferred into a $10 \mathrm{~mL}$ volumetric flask, made up to the mark with diluents, then chromatograms were obtained in triplicate as per the procedure.

\subsubsection{Linearity}

The linearity of an analytical procedure is its ability to obtain test results which are directly proportional to the concentration of analyte in the sample. The range of an analytical procedure is the interval between the upper and lower concentration of analyte for which it has been demonstrated that the analytical procedure has a suitable level of precision, accuracy and linearity. To determine linearity, different aliquots of standard stock solution $(0.5-5.0 \mathrm{~mL}$ ) were taken a series of $10 \mathrm{~mL}$ standard flasks, made up to the mark, exactly $5 \mu \mathrm{L}$ of each of these solutions was injected in triplicate, and chromatograms were obtained under the identical chromatographic conditions. Linearity plots were drawn between mean peak area of drug EMT/TDF and concentration and were presented in Figure 4 and Figure 5 respectively.

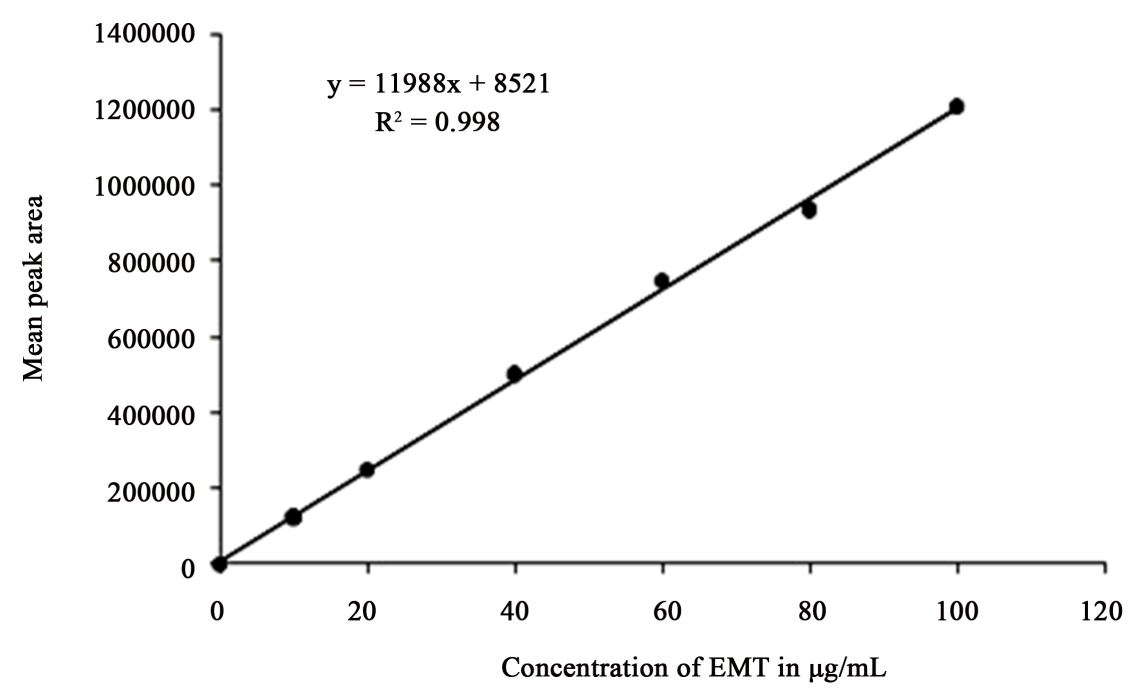

Figure 4. Linearity between mean peak area and concentration of EMT.

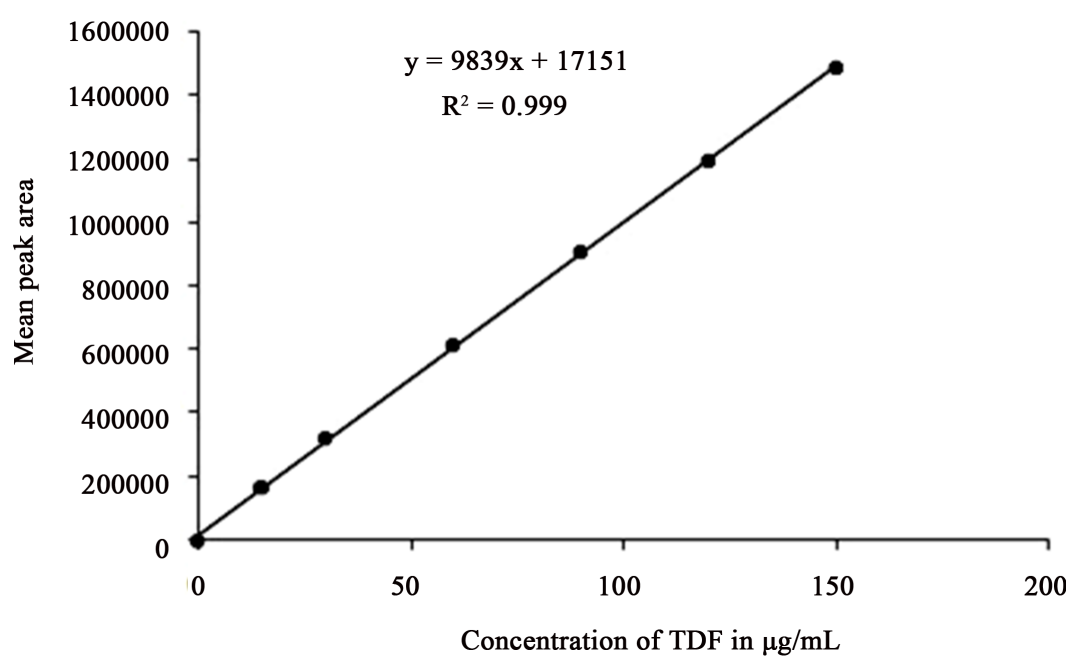

Figure 5. Linearity between mean peak area and concentration of TDF. 


\subsubsection{Limit of Detection (LOD) and Limit of Quantitation (LOQ)}

The LOD of an individual analytical procedure is the lowest amount of components in a sample which can be detected but not necessarily quantitated as an exact value. The LOQ is a parameter of quantitative assay for low levels of compounds in sample, and is used particularly for the determination of impurities and/or degradation products. To determine LOD/LOQ, exactly $0.2 / 0.15 \mathrm{~mL}$ of the sample stock solution was accurately transferred into a $10 \mathrm{~mL}$ volumetric flask and diluted up to the mark with diluents. Further pipetted $0.1 / 0.5 \mathrm{~mL}$ of the above solution was diluted to $10 \mathrm{~mL}$ and triplicate chromatograms were obtained under similar chromatographic conditions. Model chromatograms of LOD and LOQ were presented in Figure 6 and Figure 7 respectively.

\subsubsection{Robustness}

The robustness of an analytical procedure is a measure of its capacity to remain unaffected by small, but deliberate variations in $\mathrm{pH}$ of buffer, mobile phase composition, columns temperature and flow rate, and provides an indication of its reliability during normal usage. The study of robustness in the present investigation was demonstrated by carrying out deliberate variations in flow rate $1.2 \pm 0.2 \mathrm{~mL}$ and mobile phase compositions i.e. percent of organic solvent was varied from $51 \%$ to $71 \%$ ). Accurately $3.0 \mathrm{~mL}$ of sample stock solution was transferred into a $10 \mathrm{~mL}$ volumetric flask and diluted up to the mark with diluents, then exactly $5 \mu \mathrm{L}$ of the this solution was injected three times into column, chromatograms were recorded under variable conditions.

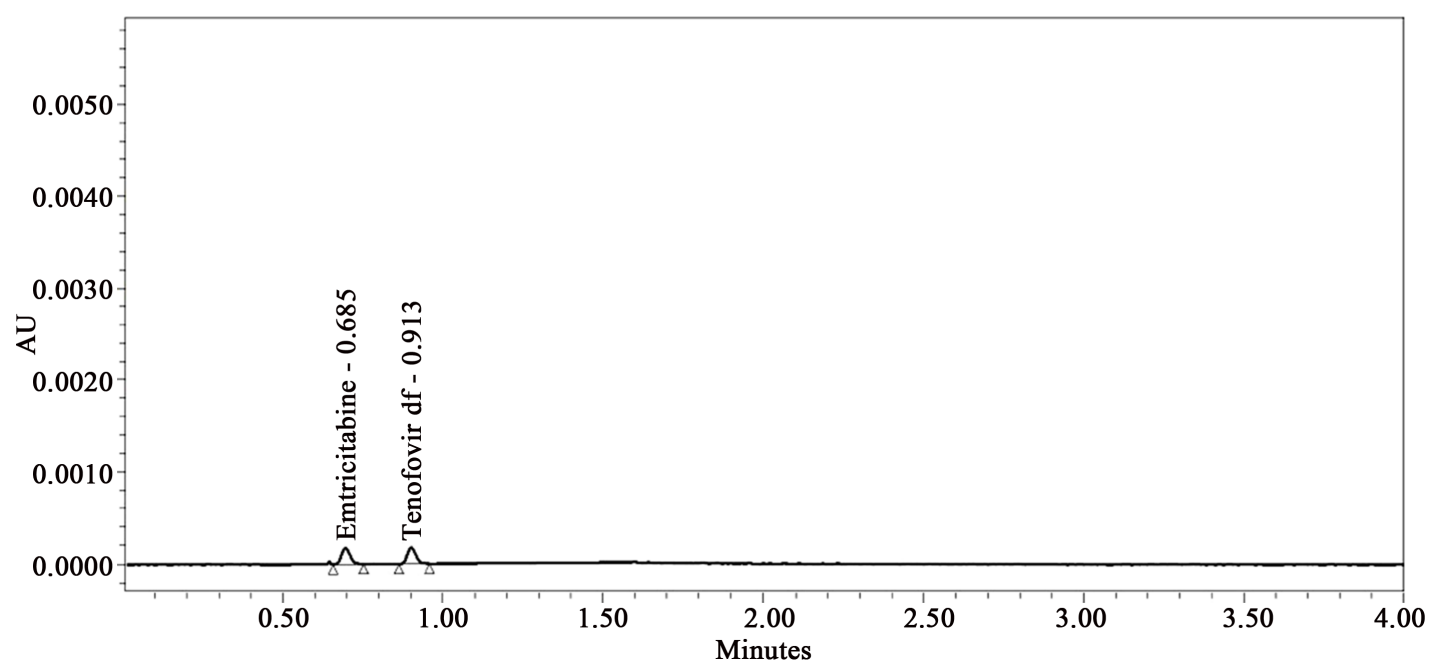

Figure 6. A typical UPLC chromatogram of EMT and TDF at LOD level.

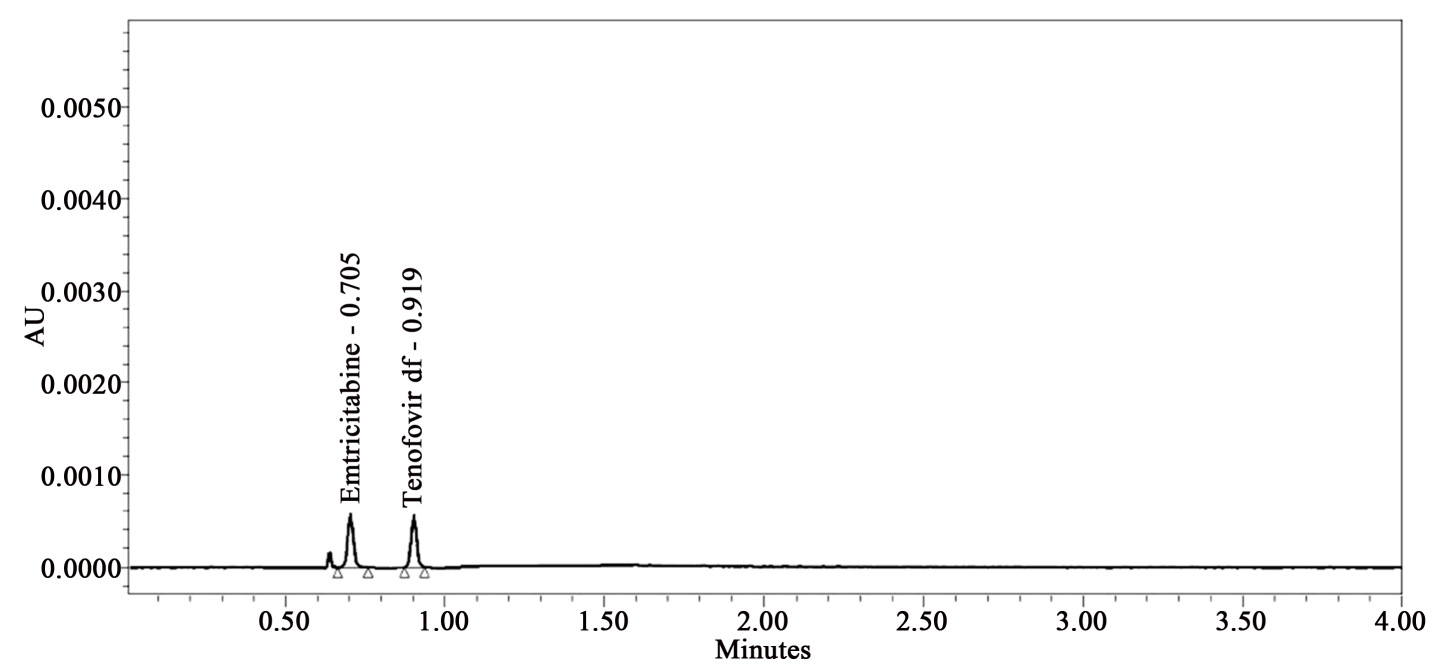

Figure 7. A typical UPLC chromatogram of EMT and TDF at LOQ level. 


\subsubsection{Ruggedness}

Ruggedness is a study of repeatability of results between two analysts, laboratories, different days and different instruments. In the present investigation the author made investigations to find the repeatability of the results between two different days. Exactly $3.0 \mathrm{~mL}$ of sample stock solution was accurately transferred into a $10 \mathrm{~mL}$ volumetric flask and diluted up to the mark with diluents, then precisely $5 \mu \mathrm{L}$ of the this solution was injected six times into column, chromatograms were recorded under the optimized conditions and chromatographic parameters were evaluated, the same procedure was repeated on two different days

\subsubsection{Specificity}

Specificity is the ability to assess unequivocally the analyte in the presence of components which may be expected to be present. Typically these might include impurities, degradants, matrix, etc. To demonstrate method specificity, exactly $5 \mu \mathrm{L}$ of blank and sample solutions were injected separately into the column and triplicate chromatograms were recorded (Figure 8 and Figure 9) under the optimized chromatographic conditions.

\subsubsection{Assay Studies}

Standard and sample stock solutions of concentration $200 \mu \mathrm{g} / \mathrm{mL}$ of EMT and $300 \mu \mathrm{g} / \mathrm{mL}$ of TDF were freshly prepared as per the procedure given in section preparation of solutions. Exactly $3.0 \mathrm{~mL}$ of standard and sample

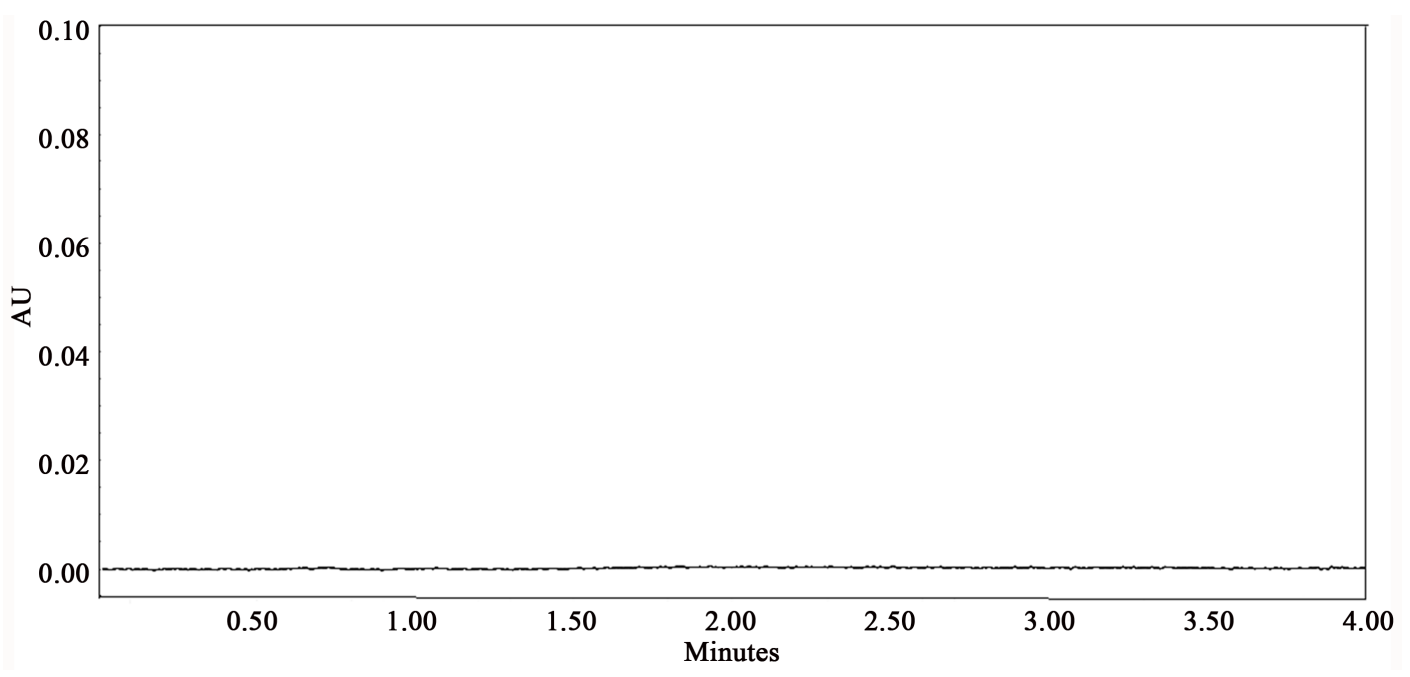

Figure 8. UPLC chromatogram of blank solution.

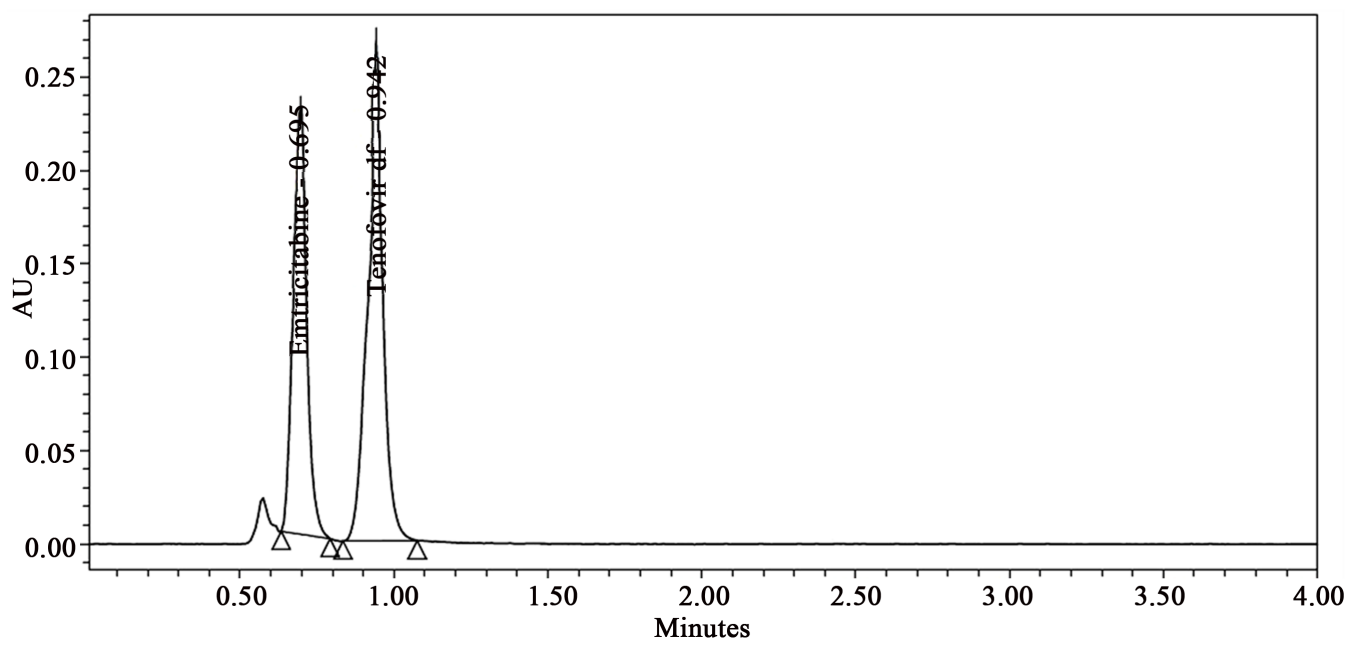

Figure 9. A typical UPLC chromatogram of EMT and TDF in sample. 
solutions were accurately transferred into two separate $10 \mathrm{~mL}$ volumetric flasks, diluted up to the mark with diluents. Precisely $5 \mu \mathrm{L}$ of each solution was injected in triplicate into column; chromatograms were obtained under the optimized chromatographic conditions.

\subsubsection{Stability Studies}

The International Conference on Harmonization (ICH) guideline entitled stability testing of new drug substances and products requires that stress testing be carried out to elucidate the inherent stability characteristics of the active substance. In this study, the drugs were exposed to different chemical and physical degradation conditions such as $0.1 \mathrm{~N} \mathrm{HCl}$ (acid hydrolysis), $0.1 \mathrm{~N} \mathrm{NaOH}$ (base hydrolysis), 3\% $\mathrm{H}_{2} \mathrm{O}_{2}$ (oxidation), heat (thermal decomposition) and UV-light (radiation decomposition) for specified time, and then diluted as similar as standard dilution, and then chromatograms were obtained under the similar chromatographic conditions, the percent of degradation was calculated from the peak area of the chromatograms. In the study of acid or base hydrolysis, an amount of fine powdered sample equivalent to $20 \mathrm{mg}$ of EMT and $30 \mathrm{mg}$ of TDF was transferred into $100 \mathrm{~mL}$ of round bottom flask and added $50 \mathrm{~mL}$ of freshly prepared $0.1 \mathrm{~N} \mathrm{HCl} / 0.1 \mathrm{~N} \mathrm{NaOH}$, shaken well and allowed for 24 hours at a temperature of $60^{\circ} \mathrm{C}$. Then filtered the solution through $0.45 \mu$ filter into $100 \mathrm{~mL}$ standard flasks and neutralized the unreacted acid or base with $0.1 \mathrm{~N} \mathrm{NaOH}$ or $0.1 \mathrm{~N} \mathrm{HCl}$ and made up to the mark. In case of peroxide degradation same amount of sample was transferred into $100 \mathrm{~mL}$ of round bottom flask, added $50 \mathrm{~mL}$ of freshly prepared $3 \% \mathrm{H}_{2} \mathrm{O}_{2}$ and refluxed at $70^{\circ} \mathrm{C}$ for 24 hours and filtered the solution through $0.45 \mu$ filter into $100 \mathrm{~mL}$ standard flasks and made up to the mark. In the study of thermal or UV-light degradation, exactly same amount of fine powdered sample was accurately transferred into a clean and dry watch glass, placed in an oven at $100^{\circ} \mathrm{C}$ or UV cabinet-254 nm for $24 \mathrm{hrs}$. Then removed from the oven or UV chamber and allowed to stand for some time at room temperature. The substance was accurately transferred into $100 \mathrm{~mL}$ volumetric flask and dissolved in diluents, filtered and made up to the mark. Exactly $3.0 \mathrm{~mL}$ of freshly prepared stock solution and solution of degraded sample was accurately transferred into separate $10 \mathrm{~mL}$ volumetric flasks and made up to the mark with diluents and chromatograms were obtained in triplicate under optimized conditions.

\section{Results and Discussion}

A precise and accurate stability indicating RP-UPLC method was developed and validated for the determination of EMT and TDF in pure and tablet dosage forms. The separation of the components was achieved by using Waters (Alliance) UPLC system equipped with auto sampler and PDA detector. The components were detected at $261 \mathrm{~nm}$ and separated by using a mobile phase of potassium dihydrogen orthophosphate buffer and methanol in the ratio $45: 55 \mathrm{v} / \mathrm{v}$ at a flow rate of $1.2 \mathrm{~mL} / \mathrm{min}$ through BEH C18 $(100 \mathrm{~mm} \times 2.1,1.8 \mu \mathrm{m})$ at ambient temperature.

\subsection{System Suitable Parameters}

Triplicate chromatograms of standard solution of concentration $60 \mu \mathrm{g} / \mathrm{mL}$ of EMT and $90 \mu \mathrm{g} / \mathrm{mL}$ of TDF were recorded. System suitable parameters such as plate count, tailing and resolution for EMT and TDF were found to be $2427 \&$ 3685, 1.16 \& 1.23 and 3.12 respectively. The chromatographic parameters like retention time, peak area and peak height of EMT and TDF were found to be 0.684 \& $0.930,694200 \& 8778000$ and $272881 \& 3685$ respectively.

\subsection{Specificity}

To determine specificity of the proposed method, number of peaks, tailing factor, number of theoretical plates, peak area and peak height of each peak, and resolution were determined. The chromatogram of sample was compared with the chromatogram of standard and found no additional peaks except two peaks at retention time 0.684 \& 0.695 and 0.930 \& 0.942 minutes for EMT and TDF respectively, where as the blank chromatogram contains no peaks. The results of specificity were presented in Table 1.

\subsection{Precision}

Precision of finite replicate measurements either in system precision or method precision is expressed as percent of relative standard deviation (\%RSD) in statistical analysis, and the acceptability should be $\%$ RSD $\leq 2.0$. In 
Table 1. Results ${ }^{*}$ of specificity (sample size: 3 ).

\begin{tabular}{|c|c|c|c|c|c|c|c|}
\hline S. No. & $\begin{array}{l}\text { Name of the } \\
\text { Component }\end{array}$ & $\begin{array}{c}\text { Retention } \\
\text { Time }\end{array}$ & Area & Peak Height & $\begin{array}{l}\text { USP Plate } \\
\text { Count }\end{array}$ & $\begin{array}{c}\text { USP } \\
\text { Tailing }\end{array}$ & $\begin{array}{c}\text { USP } \\
\text { Resolution }\end{array}$ \\
\hline Blank & -- & -- & -- & -- & -- & -- & -- \\
\hline \multirow{2}{*}{ Standard } & EMT & 0.684 & 694,200 & 272,881 & 3427.16 & 1.16 & \multirow{2}{*}{3.12} \\
\hline & TDF & 0.930 & 877,800 & 335,320 & 3685.42 & 1.23 & \\
\hline \multirow{2}{*}{ Sample } & EMT & 0.695 & 699,019 & 229,410 & 3451.24 & 1.17 & \multirow{2}{*}{2.93} \\
\hline & TDF & 0.942 & 920,324 & 267,738 & 3648.47 & 1.22 & \\
\hline
\end{tabular}

*Average of three determinations.

both cases chromatographic parameters such as peak area, peak height, retention time and resolution between two peaks were determined for six measurements. Mean peak area (M), standard deviation (SD) and percent of relative standard deviation (\%RSD) of peak area were determined using Microsoft Excel Sheet. The results of system precision and method precision were presented in Table 2 and Table 3 respectively.

\subsection{Accuracy}

To determine accuracy of the proposed method, chromatograms were obtained at three different concentration levels (10, 20 and $30 \mathrm{mg}$ of EMT and 15, 30 and $45 \mathrm{mg}$ of TDF) and the percent of recovery was evaluated at each spike level from the peak area, and then mean recovery was calculated and found to be 100.16 and 10.44 respectively. According to ICH guidelines, the mean percent of recovery should be $98 \%$ - $102 \%$, and hence the percent of recovery was within the acceptable limits. The results of accuracy were presented in Table 4.

\subsection{Linearity}

Linearity between peak area and concentration of EMT and TDF in the proposed method was determined by drawing plots taking mean peak area on y-axis against concentration on x-axis. From the plots it was evident that linearity for EMT and TDF was found to be $10-100 \mu \mathrm{g} / \mathrm{mL}$ and $15-150 \mu \mathrm{g} / \mathrm{mL}$ respectively. Slope, intercept and correlation coefficient of the data was determined using Microsoft Excel Sheet and given in Table 5.

\subsection{LOD and LOQ}

LOD and LOQ of the developed method was determined from noise-to-signal ratio method, the average baseline noise for blank and average peak area for LOD/LOQ concentration with was determined and calculated signal to noise ration and found to be more than 3.0/10.0 and found to be $0.04 \& 0.15$ and $0.06 \& 0.225$ for EMT and TDF respectively. The results were given in Table 6.

\subsection{Robustness}

In the study of robustness, chromatograms were recorded for flow rate and mobile phase composition variation, and chromatographic parameters were evaluated. It was found that there was no considerable variation in retention time, plate count, plate height, peak area for these variations. In the present investigation ruggedness of the proposed method was demonstrated between different days and different instruments. Standard deviation, percent of relative standard deviation were determined and given in Table 7.

\subsection{Ruggedness}

In the study of ruggedness, the reproducible results were obtained by the analysis of the same samples in two different days. The results of study of ruggedness were shown in Table 8.

\subsection{Analysis of Formulations}

Truvada tablets of $200 \mathrm{mg}$ Emtricitabine and $300 \mathrm{mg}$ Tenofovir Desoproxil Fumerate were analyzed by using the proposed method and satisfactory results were obtained. Peak area of both standard and test was determined 
Table 2. Results* of system precision (sample size: 6).

\begin{tabular}{ccccccc}
\hline S. No. & \multicolumn{3}{c}{ EMT } & & \multicolumn{2}{c}{ TDP } \\
\cline { 2 - 6 } & RT & Area & Height & RT & Area & Height \\
\hline 1 & 0.692 & 695,695 & 277,098 & 0.931 & 877,872 & 337,486 \\
2 & 0.688 & 694,570 & 276,650 & 0.926 & 876,526 & 336,969 \\
3 & 0.688 & 695,072 & 276,851 & 0.93 & 877,319 & 337,274 \\
4 & 0.681 & 694,997 & 276,820 & 0.925 & 875,337 & 336,512 \\
5 & 0.681 & 692,568 & 275,852 & 0.925 & 877,421 & 337,313 \\
6 & 0.675 & 693,412 & 274,391 & 0.926 & 876,549 & 338,105 \\
Maximum & 0.692 & 695,695 & 277,098 & 0.931 & 877,872 & 338,105 \\
Minimum & 0.675 & 692,568 & 274,391 & 0.925 & 875,337 & 336,512 \\
Spread & 0.017 & 3127 & 2707 & 0.006 & 2535 & 1593 \\
Mean & 0.6842 & 694,385 & 276,277 & 0.9272 & 876,837 & 337,276 \\
SD & 0.0062 & 1170.04 & 1017.36 & 0.0026 & 902.69 & 531.160 \\
RSD & 0.0091 & 0.0017 & 0.0037 & 0.0028 & 0.0010 & 0.0016 \\
\%RSD & 0.9124 & 0.1685 & 0.3682 & 0.2847 & 0.1029 & 0.1575 \\
Variance & $3.9 \mathrm{E}-05$ & $1,369,011$ & $1,035,023$ & $6.97 \mathrm{E}-06$ & $814,853.9$ & $282,131.5$ \\
\hline
\end{tabular}

*Average of six determinations; SD: Standard deviation; \%RSD: Percent of relative standard deviation.

Table 3. Results* of method precision (sample size: 6 ).

\begin{tabular}{ccccccc}
\hline S. No. & \multicolumn{3}{c}{ EMT } & \multicolumn{3}{c}{ TDP } \\
\cline { 2 - 6 } & RT & Area & Height & RT & Area & Height \\
\hline 1 & 0.682 & 695,057 & 276,844 & 0.926 & 877,779 & 337,450 \\
2 & 0.691 & 695,534 & 277,034 & 0.922 & 877,175 & 337,218 \\
3 & 0.691 & 695,099 & 276,860 & 0.928 & 879,796 & 338,226 \\
4 & 0.692 & 695,247 & 276,919 & 0.931 & 872,277 & 335,335 \\
5 & 0.686 & 696,587 & 277,453 & 0.93 & 875,568 & 336,601 \\
6 & 0.685 & 692,614 & 275,857 & 0.927 & 874,906 & 336,305 \\
Maximum & 0.692 & 696,587 & 277,453 & 0.931 & 879,796 & 338,226 \\
Minimum & 0.682 & 692,614 & 275,857 & 0.922 & 872,277 & 335,335 \\
Spread & 0.01 & 3973 & 1596 & 0.009 & 7519 & 2891 \\
Mean & 0.6878 & 695,023 & 276,827 & 0.9273 & 876,250 & 336,855 \\
SD & 0.0041 & 1309.01 & 526.39 & 0.0032 & 2600.91 & 1004.27 \\
RSD & 0.0059 & 0.0019 & 0.0019 & 0.0034 & 0.0029 & 0.0029 \\
\%RSD & 0.5917 & 0.1883 & 0.1901 & 0.3455 & 0.2968 & 0.2981 \\
Variance & $1.66 \mathrm{E}-05$ & $1,713,521$ & 277,092 & $1.03 \mathrm{E}-05$ & $6,764,754$ & $1,008,569$ \\
\hline
\end{tabular}

${ }^{*}$ The reported values are the average of six determinations; SD: Standard deviation; \%RSD: Percent of relative standard deviation. 
Table 4. Results of accuracy.

\begin{tabular}{|c|c|c|c|c|}
\hline \multirow{2}{*}{ Spiked level } & \multicolumn{2}{|c|}{ Amount } & \multirow{2}{*}{$\%$ Recovery \pm \%RSD } & \multirow{2}{*}{ Mean Recovery } \\
\hline & Added & Recovered \pm SD $^{*}$ & & \\
\hline \multicolumn{5}{|l|}{ EMT } \\
\hline $50 \%$ & 10.0 & $10.10 \pm 0.14$ & $100.62 \pm 1.38$ & \\
\hline $100 \%$ & 20.0 & $20.11 \pm 0.18$ & $100.49 \pm 0.95$ & 100.16 \\
\hline $150 \%$ & 30.0 & $29.81 \pm 0.21$ & $99.35 \pm 0.704$ & \\
\hline \multicolumn{5}{|l|}{ TDF } \\
\hline $50 \%$ & 15.0 & $15.26 \pm 0.19$ & $101.76 \pm 1.24$ & \\
\hline $100 \%$ & 30.0 & $30.10 \pm 0.25$ & $100.32 \pm 0.830$ & 100.44 \\
\hline $150 \%$ & 45.0 & $44.65 \pm 0.21$ & $99.23 \pm 0.470$ & \\
\hline
\end{tabular}

*Average of three determinations.

Table 5. Results of linearity studies.

\begin{tabular}{|c|c|c|c|c|}
\hline \multirow{2}{*}{ S. No. } & \multicolumn{2}{|c|}{ EMT $^{*}$} & \multicolumn{2}{|l|}{ TDF $^{*}$} \\
\hline & Concentration $\mu g / m L$ & Area & Concentration $\mu \mathrm{g} / \mathrm{mL}$ & Area \\
\hline 1 & 10 & 134,687 & 15 & 168,746 \\
\hline 2 & 20 & 267,989 & 30 & 320,000 \\
\hline 3 & 40 & 502,383 & 60 & 616,000 \\
\hline 4 & 60 & 700,744 & 90 & 909,858 \\
\hline 5 & 80 & 897,284 & 120 & $1,195,000$ \\
\hline \multirow[t]{5}{*}{6} & 100 & $1,130,944$ & 150 & $1,485,652$ \\
\hline & Linearity $\mu \mathrm{g} / \mathrm{mL}$ & $10-100$ & & $15-150$ \\
\hline & Slope & 11,988 & & 9839 \\
\hline & Intercept & 8521 & & 17,151 \\
\hline & Correlation coefficient & 0.9980 & & 0.9990 \\
\hline
\end{tabular}

${ }^{*}$ Average of three determinations.

Table 6. Results of limit of detection and quantitation.

\begin{tabular}{ccc}
\hline & EMT $^{*}$ & TDF $^{*}$ \\
\hline Baseline noise (N) & $\mathrm{N}=56 \mu \mathrm{V}$ & $\mathrm{N}=56$ \\
Peak area of LOD standard (S) & $\mathrm{S}=176 \mu \mathrm{V}$ & $\mathrm{S}=175$ \\
Peak area of LOQ standard (S) & $\mathrm{S}=588 \mu \mathrm{V}$ & $\mathrm{S}=586$ \\
LOD $=$ S/N & 2.98 & 2.97 \\
LOQ $=$ S/N & 9.97 & 9.93 \\
LOD concentration & $0.04 \mu \mathrm{g} / \mathrm{mL}$ & $0.06 \mu \mathrm{g} / \mathrm{mL}$ \\
LOQ concentration & $0.15 \mu \mathrm{g} / \mathrm{mL}$ & $0.225 \mu \mathrm{g} / \mathrm{mL}$
\end{tabular}

\footnotetext{
*Average of three determinations.
} 
Table 7. System suitability results in the study of robustness (sample size: 3 ).

\begin{tabular}{|c|c|c|c|c|c|c|c|}
\hline Variation & & RT & Area & Height & USP Plate Count & USP Tailing & USP Resolution \\
\hline \multirow{2}{*}{ Less flow rate } & EMT & 0.962 & 689,655 & 274,704 & 3256 & 1.21 & \multirow{2}{*}{3.17} \\
\hline & TDF & 1.223 & 870,564 & 534,677 & 3542 & 1.40 & \\
\hline \multirow{2}{*}{ More flow rate } & EMT & 0.528 & 690,657 & 275,091 & 3306 & 1.27 & \multirow{2}{*}{3.32} \\
\hline & TDF & 0.773 & 872,656 & 335,482 & 3566 & 1.10 & \\
\hline \multirow[b]{2}{*}{ Less composition } & EMT & 0.789 & 678,542 & 270,266 & 3152 & 1.32 & \multirow[b]{2}{*}{3.32} \\
\hline & TDF & 1.163 & 865,447 & 332,710 & 3515 & 1.10 & \\
\hline \multirow{2}{*}{ More composition } & EMT & 0.651 & 705,621 & 281,062 & 3306 & 1.19 & \multirow{2}{*}{2.32} \\
\hline & TDF & 0.844 & 879,564 & 338,133 & 3626 & 1.35 & \\
\hline
\end{tabular}

Table 8. Results of study of ruggedness (inter day precision).

\begin{tabular}{ccccc}
\hline \multirow{2}{*}{ Injection } & \multicolumn{2}{c}{ Day-1 } & \multicolumn{2}{c}{ Day-2 } \\
\cline { 2 - 5 } & Peak area EMT & Peak area TDF & Peak area EMT & Peak area TDF \\
\hline Injection-1 & 702,057 & 874,876 & 695,487 & 876,849 \\
Injection-2 & 696,514 & 873,175 & 701,452 & 879,542 \\
Injection-3 & 695,291 & 878,475 & 710,145 & 879,651 \\
Injection-4 & 701,244 & 873,759 & 697,849 & 879,143 \\
Injection-5 & 697,158 & 878,467 & 697,867 & 874,975 \\
Injection-6 & 693,146 & 876,812 & 701,458 & 878,453 \\
Mean & $697,568.3$ & $875,927.3$ & $700,709.7$ & $878,102.2$ \\
SD & 3454.907 & 2328.324 & 5170.628 & 1845.428 \\
\%RSD & 0.495279 & 0.265812 & 0.737913 & 0.210161 \\
\hline
\end{tabular}

for triplicate chromatograms, the percent of assay was calculated from the peak area of standard and sample, and then mean percent of assay was determined and found to be in good agreement with label claimed. The percent of assay was calculated by using the following formula. Assay $=($ Response of test/Response of standard $) \times$ (Weight of standard/Dilution of the standard) $\times($ Dilution of test/Weight of test $) \times($ Potency of the API/100) $\times$ (Average weight of formulation/Label Claimed) $\times 100$. The mean percent of assay of EMT and TDF was found to be $101.48 \%$ and $103.22 \%$ respectively and the results were presented in Table 9 .

\subsection{Stability Studies}

A study of forced degradation was carried out to evaluate the stability of the drugs in formulations. In the present investigation acid, base and peroxide degradation studies and degradation in presence of thermal energy or photo light was carried out, and the percent of degradation was calculated from the peak area of degradation standard and degraded test solution. The results of degradation and stability of drugs were presented in Table 10 .

\section{Conclusion}

The present developed isocratic RP-UPLC method was found to be simple, rapid, accurate and specific for the determination of Emtricitabine, and Tenofovir desoproxil fumerate in tablet dosages. Hence the proposed method can be adopted for the analysis for quality control in any quality control and testing laboratory. 
Table 9. Results of percent of assay.

\begin{tabular}{|c|c|c|c|c|c|c|c|c|c|c|}
\hline \multirow[b]{2}{*}{ Trade name } & \multicolumn{5}{|c|}{ EMT } & \multicolumn{5}{|c|}{ TDF } \\
\hline & LC & $\mathrm{P}$ & $\mathrm{AS}^{*}$ & $\mathrm{AT}^{*}$ & $\% A$ & LC & $\mathrm{P}$ & $\mathrm{AS}^{*}$ & $\mathrm{AT}^{*}$ & $\% A$ \\
\hline Truvada & 200 & 99.8 & 685,419 & 696,981 & 101.48 & 300 & 99.8 & 892,262 & 902,879 & 100.99 \\
\hline
\end{tabular}

LC: Label claimed; P: Purity; AS: Mean peak area for standard; AT: Mean peak area for test; \%A: \%Assay. *Average of three determinations.

Table 10. Results of degradation studies.

\begin{tabular}{|c|c|c|c|c|}
\hline & \multicolumn{2}{|c|}{ EMT } & \multicolumn{2}{|c|}{ TDF } \\
\hline & Peak area ${ }^{*}$ & \%Degradation & Peak area ${ }^{*}$ & \%Degradation \\
\hline Standard & 694,189 & -- & 877,824 & -- \\
\hline Acid & 616,370 & 11.21 & 764,848 & 12.87 \\
\hline Base & 600,126 & 13.45 & 743,253 & 15.33 \\
\hline Peroxide & 621,507 & 10.47 & 779,683 & 11.18 \\
\hline Thermal & 618,105 & 10.96 & 763,268 & 13.05 \\
\hline Photo light & 618,146 & 11.13 & 824,795 & 6.23 \\
\hline
\end{tabular}

${ }^{*}$ Average of three determinations.

\section{Acknowledgements}

The authors are thankful to Pharma Train, Pharmaceutical training and testing laboratory, Hyderabad, Telangana state, India for providing laboratory facilities and for technical support throughout the analysis.

\section{References}

[1] Anandakumar, K., Kannan, K. and Vetrichelvan, T. (2011) Development and Validation of Emtricitabine and Tenofovir Disoproxil Fumerate in Pure and in Fixed Dose Combination by UV Spectrophotometry. Digest Journal of Nanomaterials and Biostructures, 6, 1085-1090.

[2] Patel, S., Baghel, U.S., Rajesh, P., Prabhakar, D., Engla, G. and Nagar, P.N. (2009) Spectrophotometric Method Development Tenofovir Disoproxil Fumarate and Emtricitabine in Bulk Drug and Tablet Dosage Form. International Journal of Pharmaceutical and Clinical Research, 1, 28-30.

[3] Choudhari, V.P., Ingale, K.D., Barhate, A., Kale, A.N., Bobade, C.D. and Kuchekar, B.S. (2010) Development and Validation of Simultaneous and Isoabsorptive UV-Spectrophotometric Methods for Tenofovir and Emtricitabine in Pharmaceutical Formulations. Journal of Pharmacy Research, 9, 11-13.

[4] Ghorpade, S.A., Sali, M.S., Kategaonkar, A.H., Patel, D.M., Choudhari, V.P. and Kuchekar, B.S. (2010) Simultaneous Determination of Emtricitabine and Tenofovir by Area under Curve and Dual Wavelength Spectrophotometric Method. Journal of the Chilean Chemical Society, 54, 331-333. http://dx.doi.org/10.4067/s0717-97072010000100027

[5] Vishnu, P.C., Snehal, I., Sacchidanand, R.G., Dipali, D.T., Vikram, G.M. and Ambekar, A. (2011) Spectrophotometric Simultaneous Determination of Tenofovir Disoproxil Fumarate and Emtricitabine in Combined Tablet Dosage Form by Ratio Derivative, First Order Derivative and Absorbance Corrected Methods and Its Application to Dissolution Study. Pharmaceutical Methods, 2, 47-52. http://dx.doi.org/10.4103/2229-4708.81096

[6] Ahindita, P., Aurobinda, K.M., Amit, G.S., Dannana, K., Swapna, M. and Sudam, C.S.I. (2010) Development and Validation of Spectrophotometric Methods for Determination of Emtricitabine and Tenofovir Disoproxil Fumarate in Bulk and Tablet Dosage Form. International Journal of PharmTech Research, 3, 1874-1882.

[7] Ghorpade, S.A., Sali, K.A.H., Patel, D.M., Choudhari, V.P. and Kuchekar, B.S. (2010) Simultaneous Determination of Emtricitabine and Tenofovir by Area under Curve and Dual Wavelength Spectrophotometric Method. Journal of the Chilean Chemical Society, 55, 115-117. http://dx.doi.org/10.4067/S0717-97072010000100027

[8] Choudhari, V.P., Ingale, S., Gite, S.R., Tajane, D.D., Modak, V.G. and Ambekar, A. (2011) Spectrophotometric Simultaneous Determination of Tenofovir Disoproxil Fumarate and Emtricitabine in Combined Tablet Dosage Form by Ratio Derivative First Order Derivative and Absorbance Corrected Methods and Its Application to Dissolution Study. Pharmaceutical Methods, 1, 47-52. http://dx.doi.org/10.4103/2229-4708.81096 
[9] Karunakaran, A., Kamarajan, K. and Thangarasu, V. (2010) A Validated RP-HPLC Method for Simultaneous Estimation of Emtricitabine and Tenofovir Disoproxil Fumarate in Pure and in Tablet Dosage Form. Pharm Sin, 1, 52-60.

[10] Sharma, R. and Gupta, P. (2009) A Validated RP-HPLC Method for Simultaneous Estimation of Emtricitabine and Tenofovir Disoproxil Fumarate in a Tablet Dosage Form. Eurasian Journal of Analytical Chemistry, 4, 276-284.

[11] Pranitha, D., Vanitha, C. and Francies, P. (2010) Simultaneous Estimation of Emtricitabine, Tenofovir Disoproxil Fumarate and Rilpivirine in Bulk Form by RP-HPLC Method. Journal of Pharmacy Research, 5, 4600-4602.

[12] Raju, N.A. and Begum, S. (2008) Simultaneous RP-HPLC Method for the Estimation of the Emtricitabine, Tenofovir Disoproxil Fumarate and Efavirenz in Tablet Dosage Forms. Research J Pharm Technol, 1, 522-525.

[13] Rezk, N.L., Crutchley, R.D. and Kashuba, A.D. (2005) Simultaneous Quantification of Emtricitabine and Tenofovir in Human Plasma Using High-Performance Liquid Chromatography after Solid Phase Extraction. Journal of Chromatography B, 822, 201-208. http://dx.doi.org/10.1016/j.jchromb.2005.06.019

[14] Nirogi, R., Bhyrapuneni, G., Kandikere, V., Mudigonda, K., Komarneni, P., Aleti, R., et al. (2009) Simultaneous Quantification of a Non-Nucleoside Reverse Transcriptase Inhibitor Efavirenz, a Nucleoside Reverse Transcriptase Inhibitor Emtricitabine and a Nucleotide Reverse Transcriptase Inhibitor Tenofovir in Plasma by Liquid Chromatography Positive Ion Electrospray Tandem Mass Spectrometry. Journal of Chromatography, 23, 371-381. http://dx.doi.org/10.1002/bmc.1125

[15] Gomes, N.A., Vaidya, V.V., Pudage, A., Joshi, S.S. and Parekh, S.A. (2008) Liquid Chromatography-Tandem Mass Spectrometry Method for Simultaneous Determination of Tenofovir and Emtricitabine in Human Plasma and Its Application to a Bioequivalence Study. Journal of Pharmaceutical and Biomedical Analysis, 48, 918-926. http://dx.doi.org/10.1016/j.jpba.2008.07.022

[16] Delahunty, T., Bushman, L., Robbins, B. and Fletcher, C.V. (2009) The Simultaneous Assay of Tenofovir and Emtricitabine in Plasma Using LC/MS/MS and Isotopically Labeled Internal Standards. Journal of Chromatography B, 877, 1907-1914. http://dx.doi.org/10.1016/j.jchromb.2009.05.029

[17] Avolio, A.D., Sciandra, M. and Siccardi, M. (2008) A New Assay Based on Solid-Phase Extraction Procedure with LC-MS to Measure Plasmatic Concentrations of Tenofovir and Emtricitabine in HIV Infected Patients. Journal of Chromatographic Science, 46, 524-528. http://dx.doi.org/10.1093/chromsci/46.6.524

[18] Yadav, M., Singhal, P., Goswami, S., Pande, U.C., Sanyal, M. and Shrivastav, P.S. (2010) Selective Determination of Antiretroviral Agents Tenofovir, Emtricitabine, and Lamivudine in Human Plasma by a LC-MS-MS Method for a Bioequivalence Study in Healthy Indian Subjects. Journal of Chromatographic Science, 48, 704-713. http://dx.doi.org/10.1093/chromsci/48.9.704

[19] Joshi, M., Nikalje, A.P., Shahed, M. and Dehghan, M. (2009) HPTLC Method for the Simultaneous Estimation of Emtricitabine and Tenofovir in Tablet Dosage Form. Indian Journal of Pharmaceutical Sciences, 71, 95-97. http://dx.doi.org/10.4103/0250-474X.51951

[20] Kavitha, K.Y., Geetha, G., Hariprasad, R., Venkatnarayanan, R. and Kaviarasu, M. (2013) Development and Validation of RP-UPLC Analytical Method for Simultaneous Estimation of the Emtricitabine, Tenofovir Disoproxil Fumarate and Rilpivirine and Its Pharmaceutical Dosage Form. International Research Journal of Pharmacy, 4, 150-155.

[21] Nagaraju, P.T., Channabasavaraj, K.P. and Shantha Kumar, P.T. (2011) Development and Validation of Spectrophotometric Method for Estimation of Emtricitabine in Tablet Dosage Form. International Journal of ChemTech Research, 3, 23-28.

[22] Droste, J.A.H., Aarnoutse, R.E. and Burger, D.M. (2007) Determination of Emtricitabine in Human Plasma Using HPLC with Fluorometric Detection. Journal of Liquid Chromatography \& Related Technologies, 30, 2769-2778. http://dx.doi.org/10.1080/10826070701560900

[23] Ashenafi, D., Verbeek, A., Hoogmartens, J. and Adams, E. (2009) Development and Validation of an LC Method for the Determination of Emtricitabine and Related Compounds in the Drug Substance. Journal of Separation Science, 32, 1823-1830. http://dx.doi.org/10.1002/jssc.200800688

[24] Seshachalam, U., Haribabu, B. and Chandrasekhar, K.B. (2007) Development and Validation of a Stability-Indicating Liquid Chromatographic Method for Determination of Emtricitabine and Related Impurities in Drug Substance. Journal of Separation Science, 30, 999-1004. http://dx.doi.org/10.1002/jssc.200600429

[25] Pendela, M., Mamade, D.A., Hoogmartens, J., Van Schepdael, A. and Adams, E. (2010) Characterization of Emtricitabine Related Substances by Liquid Chromatography Coupled to an Ion Trap Mass Spectrometer. Talanta, 82, 125-128. http://dx.doi.org/10.1016/j.talanta.2010.04.004

[26] Atul, H.B. and Charashila Sajai, J.S. (2009) Application of UV-Spectrophotometric Methods for Estimation of Tenofovir Disoproxil Fumarate in Tablets. Pakistan Journal of Pharmaceutical Sciences, 22, 27-29.

[27] Pratap Reddy, J. and Chakravarthy, I.E. (2012) New Spectrophotometric Determination of Tenofovir Disoproxil Fumaratein Bulk and Pharmaceutical Dosage Form. IOSR Journal of Applied Chemistry, 1, 29-33. 
http://dx.doi.org/10.9790/5736-0122933

[28] Rani, T.S., Sujatha, K. and Chitra, K. (2012) Spectrophotometric Methods for Estimation of Tenofovir Disoproxil Fumarate in Tablet. J Pharm Anal, 1, 9-12.

[29] Onah, J.O. and Ajima, U. (2011) Spectrophotometric Determination of Tenofovir Disoproxil Fumarate after Complexation with Ammonium Molybdate and Picric Acid. International Journal of Drug Development and Research, 3, 199 204.

[30] Kandagal, P.B., Manjunatha, D.H., Seetharamappa, J. and Kalanur, S.S. (2008) RP-HPLC Method for the Determination of Tenofovir in Pharmaceutical Formulations and Spiked Human Plasma. Analytical Letters, 41, 561-570. http://dx.doi.org/10.1080/00032710801910742

[31] Jullien, V., Tréluyer, J.M., Pons, G. and Rey, E. (2003) Determination of Tenofovir in Human Plasma by High-Performance Liquid Chromatography with Spectrofluorimetric Detection. Journal of Chromatography B, 785, 377-381. http://dx.doi.org/10.1016/S1570-0232(02)00933-9

[32] Sparidans, R.W., Crommentuyn, K.M.L., Schellens, J.H.M. and Beijnen, J.H. (2003) Liquid Chromatographic Assay for the Antiviral Nucleotide Analogue Tenofovir in Plasma Using Derivatization with Chloroacetaldehyde. Journal of Chromatography B, 791, 227-233. http://dx.doi.org/10.1016/S1570-0232(03)00225-3

[33] Bhavsar, S., Patel, B.N. and Patel, C.N. (2012) RP-HPLC Method for Simultaneous Estimation of Tenofovir Disoproxil Fumarate, Lamivudine, and Efavirenz in Combined Tablet Dosage Form. Pharm Methods, 3, 73-78. http://dx.doi.org/10.4103/2229-4708.103876

[34] Barkil, M.E., Gagnieu, M. and Guitton, J. (2007) Relevance of a Combined UV and Single Mass Spectrometry Detection for the Determination of Tenofovir in Human Plasma by HPLC in Therapeutic Drug Monitoring. Journal of Chromatography B, 54, 192-197. http://dx.doi.org/10.1016/j.jchromb.2007.04.015

[35] Sentenac, S., Fernandez, C., Thuillier, A., Lechat, P. and Aymard, G. (2003) Sensitive Determination of Tenofovir in Human Plasma Samples Using Reversed-Phase Liquid Chromatography. Journal of Chromatography B, 793, 317-324. http://dx.doi.org/10.1016/S1570-0232(03)00333-7 